\title{
MOVIMENTOS MIGRATÓRIOS INTERNOS EM PORTUGAL (1995-2011) \\ Caracterização exploratória considerando grupos de idades, níveis de habilitações e atividade
}

\author{
Maria Cristina Sousa Gomes \\ Unidade de Investigação GOVCOPP, Universidade de Aveiro, Aveiro, Portugal
}

\section{Maria João Guardado Moreira}

Escola Superior de Educação do Instituto Politécnico de Castelo Branco, Castelo Branco, Portugal

Centro de Estudos da População, Economia e Sociedade - CEPESE, Porto, Portugal

Maria Luís Rocha Pinto

Unidade de Investigação GOVCOPP, Universidade de Aveiro, Aveiro, Portugal

Resumo Portugal não dispõe de instrumentos que permitam uma análise aprofundada dos seus movimentos migratórios internos, apesar da sua importância na dinâmica populacional. Neste artigo partimos dos dados do questionário individual do censo de 2001, em que se perguntava a cada indivíduo se residia no concelho em que é recenseado nos dois e cinco anos anteriores, e dos globais de 2011 relativos à mesma pergunta. Concluímos que, nos dois censos, mais de $6 \%$ do total dos residentes num determinado concelho, migraram em data anterior pelo menos uma vez, e cerca de $2 \%$ do total de residentes tiveram residência anterior no estrangeiro. Por outro lado, em 2001, considerando o desenvolvimento dos dados trabalhados, os que se moveram dispunham de mais habilitações do que a média da população portuguesa no mesmo grupo etário e mostravam níveis mais elevados de emprego.

Palavras-chave: migrantes, mobilidade interna, migrantes do estrangeiro, fluxos migratórios.

Abstract Portugal does not possess the instruments to enable a deep analysis of its internal migration trends despite the importance these trends represent in the population dynamics. This paper is based on data of the 2001 INE databases of the individual census in which each person was asked if he/she lived in the municipality where the census was being taken. This residence refers to the previous two and five years. This paper also addresses the 2011 global data regarding the same question. We concluded that, in both cases, more than $6 \%$ of the total residents of a municipality had migrated at least once before and about $2 \%$ of the residents had lived abroad. Furthermore, in 2001 considering the developed data, those who moved were more qualified than the average Portuguese population of the same age group and showed higher levels of employment.

Keywords: migrants, internal mobility, migrants from abroad, migratory flows.

Résumé Le Portugal ne dispose pas d'instruments permettant une analyse approfondie de ses mouvements migratoires internes, en dépit de leur importance dans la dynamique de la population. Dans cet article, nous partons des données dans les bases de l'INE, du questionnaire individuel du recensement de 2001, dans lequel il est demandé à chaque individu s'il résidait dans la municipalité où il est recensé dans les deux et les cinq années précédentes, et des données globales de 2011 concernant la même question. En conclusion, dans les deux recensements, plus de $6 \%$ du total de résidents d'une municipalité avaient migré au moins une fois précédemment et environ $2 \%$ des résidents avaient résidé à l'étranger. Par ailleurs, en 2001 en considérant les donnés approfondies, ceux qui ont déménagé étaient plus qualifiés que la moyenne de la population portugaise dans le même groupe d'âge et montraient des niveaux d'emploi plus élevés.

Mots-clés: migrants, mobilité interne, migrants venus de l'étranger, flux migratoires.

Resumen Portugal no dispone de instrumentos que permitan un profundo análisis de sus movimientos migratorios internos, a pesar de la importancia que estos tienen en su dinámica poblacional. En este artículo partimos de los datos del cuestionario individual del censo de 2001, en el cual se pregunta a cada individuo si residía en el municipio en que está censado en los dos y cinco años anteriores, y de los datos globales del censo 
de 2011, en relación con la misma pregunta. Concluimos que, en los dos censos, más del 6\% del total de los residentes en un determinado municipio emigraron por lo menos una vez y, además, cerca del $2 \%$ de ellos tuvieron residencia anteriormente en el extranjero. Por otro lado, en 2001, teniendo en cuenta el desarrollo de los datos trabajados, los que emigraron contaban con mayor nivel académico y mostraban niveles más elevados de empleo que la media de la población portuguesa en el mismo grupo etario.

Palabras-clave: inmigrantes, movilidad interna, migrantes desde el extranjero, flujos migratorio.

\section{Introdução}

Portugal não dispõe de instrumentos que permitam uma análise aprofundada dos seus movimentos migratórios internos, apesar da importância destes na dinâmica populacional. ${ }^{1}$ De facto, a evolução populacional portuguesa foi impulsionada e condicionada por este tipo de mobilidade, nomeadamente no que respeita à concentração urbana ou à litoralização, verficando-se, ainda hoje, repercursões nas características e dinâmicas regionais. A análise e tratamento dos movimentos migratórios internos corresponde sempre a análises indiretas, mais ou menos grosseiras, e que nunca permitem um tratamento demográfico integral, sendo disso exemplo trabalhos como os de Alarcão (1964), Evangelista (1971), Ferrão (1996) e Pinto e Rodrigues (1996), com as consequências que este facto implica na análise dos contextos socioeconómicos.

O questionário individual dos recenseamentos portugueses, a partir de 1981, inclui duas perguntas que permitem uma análise um pouco mais precisa das características destes migrantes. Referimo-nos às questões em que se pergunta a cada indivíduo se reside no concelho em que é recenseado em duas datas anteriores, correspondendo a cerca de dois anos antes e cinco anos antes. Contudo, nas publicações dos censos, assim como na informação disponível nas bases de dados do INE, apenas estão disponíveis os dados globais quanto à população que mudou de concelho (proveniente do estrangeiro, ou que mudou de/para outro concelho). Para uma análise mais detalhada recorreu-se a um apuramento de dados recolhidos no censo de 2001. Foi no âmbito do projeto que integramos ("Economically Sustainable DEMOgraphy - ReverSing Decline in Peripheral RegioNs (DEMOSPIN) PTDC/CS-DEM/100530/2008") que tivemos acesso a esta informação para o censo de 2001. Será, portanto, sobre os dados disponíveis do censo de 2001 que a nossa análise se centrará neste artigo, o que corresponde a um primeiro tratamento relativamente a uma investigação mais aprofundada que está em curso. No entanto, de forma muito global, compararemos estes movimentos para 2001 e 2011 com os dados que estão disponíveis.

Faremos, assim, uma análise descritiva e que neste trabalho exploratório deixará de lado a informação segundo o sexo. Optámos igualmente por apenas tratar

1 Uma primeira versão deste artigo foi apresentada no X Congresso Internacional da ADEH Albacete, 18 a 21 de junho de 2013. 
os dados disponíveis para os residentes de 2001 que em 1995 residiam em outro concelho ou no estrangeiro.

O conhecimento da residência dos indivíduos em datas anteriores aos censos não nos permite medir os movimentos migratórios internos, mas apenas elaborar uma aproximação aos fluxos populacionais que revelará os concelhos que mais perderam ou beneficiaram com esta mobilidade, face às datas em análise. Esta limitação deve-se a que nada impede que entre as datas tratadas, ou desde o censo anterior, um indivíduo não tenha tido outros momentos de mobilidade, ou que indivíduos residentes num qualquer concelho que permanece o mesmo no momento do censo não tenha tido períodos de mobilidade, quer entre dois censos, quer entre as datas que são analisadas. Por exemplo, um indíviduo que em 1996 residisse em outro concelho, mas não em 1995, e em 2001 residisse no concelho em análise não surge nestes valores.

Sem poder medir verdadeiramente os migrantes, este estudo permite uma primeira caracterização dos indivíduos que mudaram de residência entre a data referenciada e a data do recenseamento.

Uma nota ainda quanto à impossibilidade de distinção da nacionalidade dos que, tendo residido no estrangeiro em 1995, residiam em 2001 num qualquer concelho em Portugal, uma vez que a base de dados com que trabalhámos não o permitia.

\section{Enquadramento da problemática: algumas considerações}

As migrações internas, importantes ao nível da dinâmica populacional, adquirem uma acuidade acrescida a uma escala local, quer pela reconhecida capacidade de rápida renovação da população (Dasre et al., 2009; Cauchi-Duval, Jourdan e N'Diaye, 2006), quer, também, pelo processo oposto de diminuição da dinâmica populacional, provocando o envelhecimento da mesma. Este(s) movimento(s) de entrada e saída, de atração e/ou repulsão acaba $(\mathrm{m})$ por ter efeitos regionais muito diversificados, muitas vezes contrastantes. O seu conhecimento é, portanto, indispensável para a compreensão dos processos de desenvolvimento do território, seja pela criação de atividades socioeconómicas, seja pelo seu enfraquecimento.

Porém, comparativamente à fecundidade, mortalidade e migrações internacionais, as migrações internas têm sido alvo de menor atenção, como o reconhecem Bell et al. (2002: 435). Os mesmos autores referem que, embora existam alguns trabalhos de análise e de comparação, encontram-se limitações que se devem às próprias características do fenómeno (migrações internas).

Apesar dos vários trabalhos de investigação divulgados, este campo de análise tem ainda muito em aberto, tal como Courgeau e Lelièvre (2003:167) referem:

[...] il reste encore beaucoup à faire pour mettre en place une théorie expliquant le rôle des divers niveaux d'agrégation sur les comportements migratoires. On peut dès lors se demander s'il existe des niveaux d'agrégation plus pertinents que d'autres à faire intervenir pour comprendre les comportements migratoires. Il y a donc là tout un 
champ, à la fois théorique et empirique, dont on commence juste l'exploration et que nécessitera encore de nombreuses études à venir.

A análise das migrações internas constitui, como se pode depreender, um campo complexo, mas simultaneamente um objeto particularmente pertinente na análise da evolução populacional. É com base nos dados censitários que muitos trabalhos de investigação decorrem, nomeadamente os de Nicholson (1990) e Borjas (2006), outros, com recurso a bases de dados complementares, comparam e alargam o âmbito da análise, como acontece com Royer (2009). No caso espanhol, a publicação anual da Estatística de Variaciones Residenciales, a par da exploração de perguntas sobre migrações incluídas nos censos, tem permitido, desde os anos 60, um conhecimento sistemático da mobilidade interna naquele país, embora com algumas limitações que decorrem do processo de recolha dos dados (Bendito, 1999; Recaño e Cabré, 2003; Cabré, Pujadas e Moreno, 1985; Cabré e Recaño, 1997; Pujadas e García Coll, 1995; Coll e Puyol, 1997; Recaño, 2004b; 2004a; 2006).

Outros autores, na análise da mobilidade populacional, recorrem aos dados do recenseamento obtidos a partir do registo do local de residência anterior ao momento censitário (Courgeau, 1973; Courgeau e Lelièvre, 2003; Baccaini, 1999; 2007; Courgeau, Lelièvre e Rogers, 2002). Reconhece-se, todavia, as limitações que decorrem da própria forma de recolha, o que conduz a apenas se dispor de uma aproximação (Baccaini, 1999: 801).

No entanto, segundo Baccaini, esta pergunta particular do censo, apesar das limitações, possibilitou a "publicação das principais estatísticas sobre as migrações internas em França" (1999: 801).

De facto não são muitos os trabalhos que em Portugal se têm debruçado sobre estes dados, apesar de, já em 1985, Custódio Cónim mencionar o “desconhecimento estatístico dos fluxos migratórios internos" numa análise das migrações internas em 1981 (1985: 11). A investigação existente, conta com trabalhos como os de Emília Saleiro e Pedro Campos (1994), com uma análise sobre migrações internas na região Norte; de Vasco Lucas (1997), que analisa o retorno de emigrantes na região Centro; de João Peixoto (1998), que caracterizou os migrantes inter-regionais durante a década de 1980; e de Cristina Oliveira e João Peixoto (2001) que, com base nos dados do Inquérito ao Emprego, estudam as migrações internas inter-regionais no Continente entre 1992 e 1999. De referir, relativamente ao período de 1991-2001, o trabalho de Maria Roca e Dulce Pimentel (2003), em que procuram encontrar causas explicativas para as migrações internas; também em 2003 Graça Magalhães analisou o impacto dos fluxos inter-regionais na evolução da população, de modo a possibilitar a incorporação destes dados em projeções da população. Mais recentemente Mendes, Caleiro, Lagarto e Ribeiro (2009) propuseram uma metodologia de análise para estes movimentos a nível de NUT II.

Não tivemos aqui a pretensão de abordar todos os trabalhos, embora tenhamos consciência que, com diferentes perspetivas analíticas e científicas, esta temática tem vindo a atrair vários investigadores portugueses. 


\section{Evolução dos fluxos / mobilidade em Portugal entre 2001 e 2011}

Para uma visão global dos volumes dos movimentos por concelho dispomos de informação para 2001 e 2011, pelo que serão abordados os dados destes dois censos (figuras 1 e 2).

Tomando como referência uma única data anterior aos recenseamentos, respetivamente 31/12/1995 e 31/12/2005, podemos constatar que, em 2001, 679.894 indivíduos (6,6\% da população) mudaram de concelho de residência. Em 2011 eram 678.389 (6,4\% da população) os indivíduos que mudaram de concelho de residência.

Considerando a mudança de residência do estrangeiro, isto é, dos indivíduos que anteriormente residiam no estrangeiro, em 2001 são 245.055 (2,4\% da população) os que declaram ter mudado de residência, e em 2011 são 215.130 (2,2\% da população).

Como se pode depreender por estes valores é muito significativa a mobilidade residencial da população portuguesa. Mais de $6 \%$ do total dos residentes num determinado concelho migraram em data anterior pelo menos uma vez. É um facto que estas migrações poderão ter significados muito diferentes e que só o aprofundamento da investigação nos poderá dar melhores elementos de caracterização destes movimentos. Assim, por exemplo, não têm o mesmo significado, sob o ponto de vista socioeconómico, uma migração entre concelhos limítrofes ou para concelhos muito mais distantes, uma migração do interior para o interior do país ou do interior para o litoral, do litoral para o interior ou ainda do litoral para o litoral.

Também os valores relativos aos indivíduos que vieram do estrangeiro nos permitem percecionar quantitativos que, à nossa dimensão, são significativos. Aqui a análise torna-se mais restritiva, dado que estes valores ignoram, por completo, a emigração, seja ela a de nacionais ou de anteriores residentes estrangeiros em Portugal. Mesmo assim será possível um estudo mais aprofundado desta realidade, se pudermos vir a cruzar estes dados com outras fontes de informação, dado que não nos foi possível distinguir entre as entradas de estrangeiros e de nacionais que regressam ao país.

Dispomos dos valores destes movimentos a nível de concelho e será a esse nível que o desenvolvimento desta investigação deverá trabalhá-los; aqui cingir-nos-emos a uma leitura global dos cartogramas resultantes do cálculo das percentagens dos residentes em cada concelho em 2001 e 2011 que em 1995 e em 2005 residiam em outro concelho do país ou no estrangeiro. Resultaram assim quatro cartogramas que analisaremos brevemente (figuras 1 e 2).

A apresentação da figura 1 exige que alertemos para o facto de os repetivos cartogramas poderem ser apresentados de forma inversa. Ou seja, a partir dos concelhos aonde os indivíduos residiam, quer em 1995 quer em 2005. Assim, as imagens corresponderiam aos concelhos que perderam esta população, enquanto neste caso correspondem aos concelhos que "ganharam" esta população. De qualquer modo, o que se torna mais interessante verificar nestes cartogramas é o facto de todos os concelhos terem recebido população de um qualquer outro concelho do país. No caso de 2001, nenhum concelho recebeu menos de $1,1 \%$ da sua 


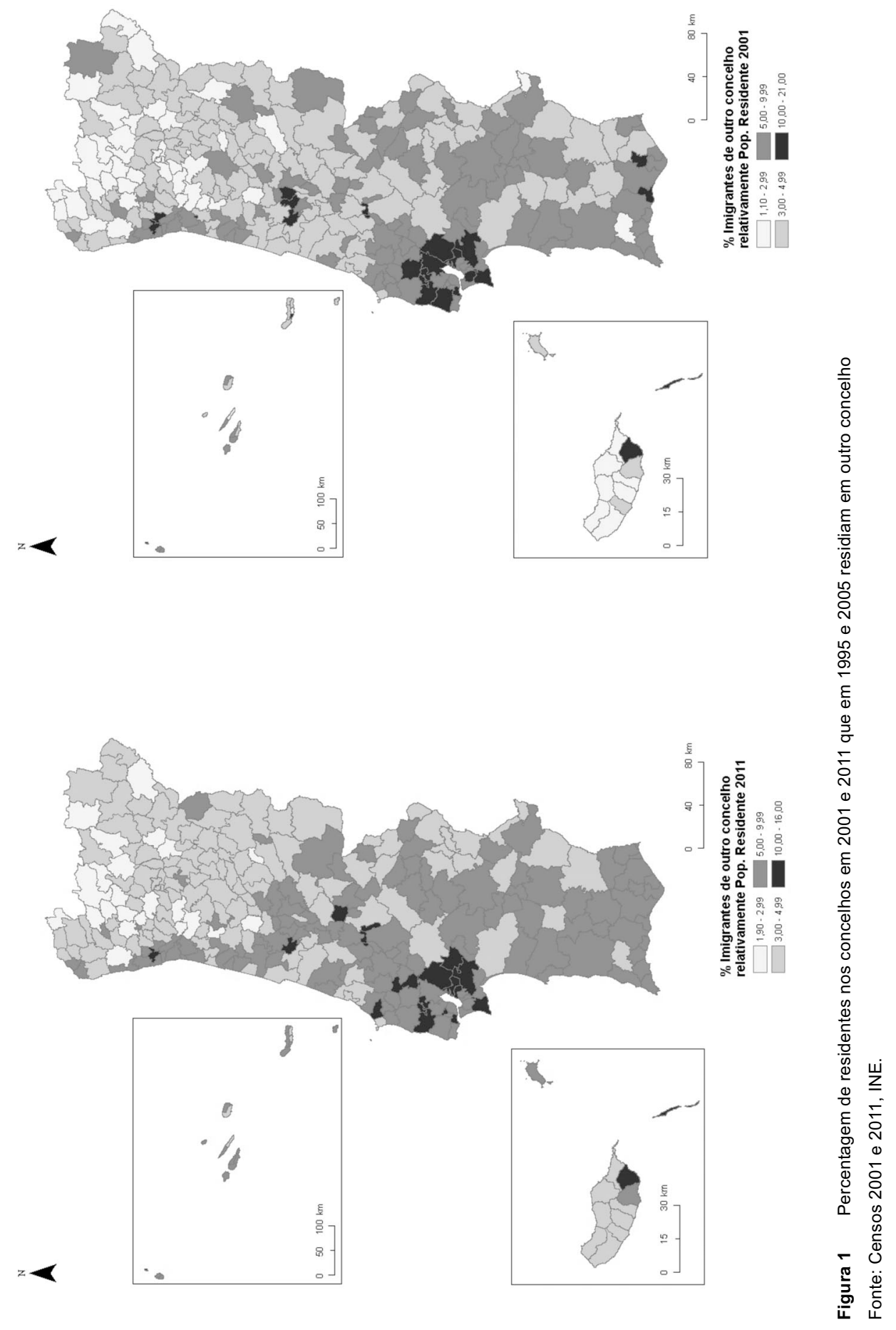


população residente e, em 2011, este valor sobe para 1,9\%. Os valores máximos atingiram 21\% em 2001 (concelho de Sesimbra) e 16\% em 2011 (concelho de Alcochete). Em qualquer dos dois censos em análise podemos verificar que é o Sul do país que concentra uma maior percentagem de residentes oriundos da mobilidade, com maior expressão em 2011. Os Açores não revelam valores dignos de nota e apenas na Madeira os concelhos de Santa Cruz e do Funchal revelam um poder de atração significativo em ambas as datas. Só uma análise mais fina nos permitiria uma aproximação às características destes migrantes por concelho ou região, assim como às causas da sua mobilidade, mas neste caso estes valores terão de ser necessariamente contrabalançados pelas saídas de cada um dos concelhos.

Se olharmos agora a figura 2, os respetivos cartogramas, que traduzem a percentagem de indivíduos que em 1995 e 2005 residiam no estrangeiro relativamente à sua residência em 2001 e 2011 respetivamente, as manchas no território diferem muito das anteriores. Os cartogramas revelam que, globalmente, é a norte da região de Lisboa que se concentram mais indivíduos vindos do estrangeiro, embora de forma mais intensa em 2001 do que em 2011. Em 2001 a região de Lisboa e o Algarve, prolongando-se um pouco pelo sul do Alentejo, são também regiões de residência de população vinda do estrangeiro. Consideramos que estas duas manchas poderão corresponder a diferentes tipos de movimentos a aprofundar no futuro, mas que concentrariam a norte indivíduos portugueses emigrantes no estrangeiro e que regressaram ao país, enquanto a região de Lisboa e o Sul concentrariam uma população constituída maioritariamente por estrangeiros. No caso do Algarve, o trabalho de Dora Sampaio (2010) remete-nos para uma significativa imigração pós-reforma de estrangeiros. Em 2011 o panorama aproxima-se do de 2001, mas com intensidades menores. A percentagem de residentes oriundos do estrangeiro não assume a mesma dimensão que nos migrantes internos, mas são inúmeros os concelhos em que estes residentes se situam entre os $4 \%$ e os $7,9 \%$ em 2001 , e entre os $4 \%$ e os $9 \%$ em 2011. Cabe aqui ainda uma palavra para a Madeira, que revela um acolhimento de indivíduos vindos do estrangeiro com significado (valores acima de 4\% da população residente), quer em 2001 quer em 2011, particularmente em três concelhos (Calheta, Porto Moniz e São Vicente) que, paradoxalmente, perderam população entre 2001 e 2011.

Em termos de mancha territorial as zonas de menor atração de indivíduos que residiam no estrangeiro, tanto em 1995 como em 2005, situam-se no Alto Alentejo (em 2001 também se estendem ao Alentejo Litoral) e na Lezíria do Tejo, assim como no Tâmega, com extensões ao Grande Porto.

Embora sem a dimensão dos movimentos internos, podemos afirmar que não existe nenhum concelho em Portugal que, quer em 2001 relativamente a 1995, quer em 2011 relativamente a 2005, não tenha acolhido população vinda do exterior das fronteiras portuguesas, independentemente de esta população ser constituída por imigrantes ou por nacionais que regressaram ao país. 

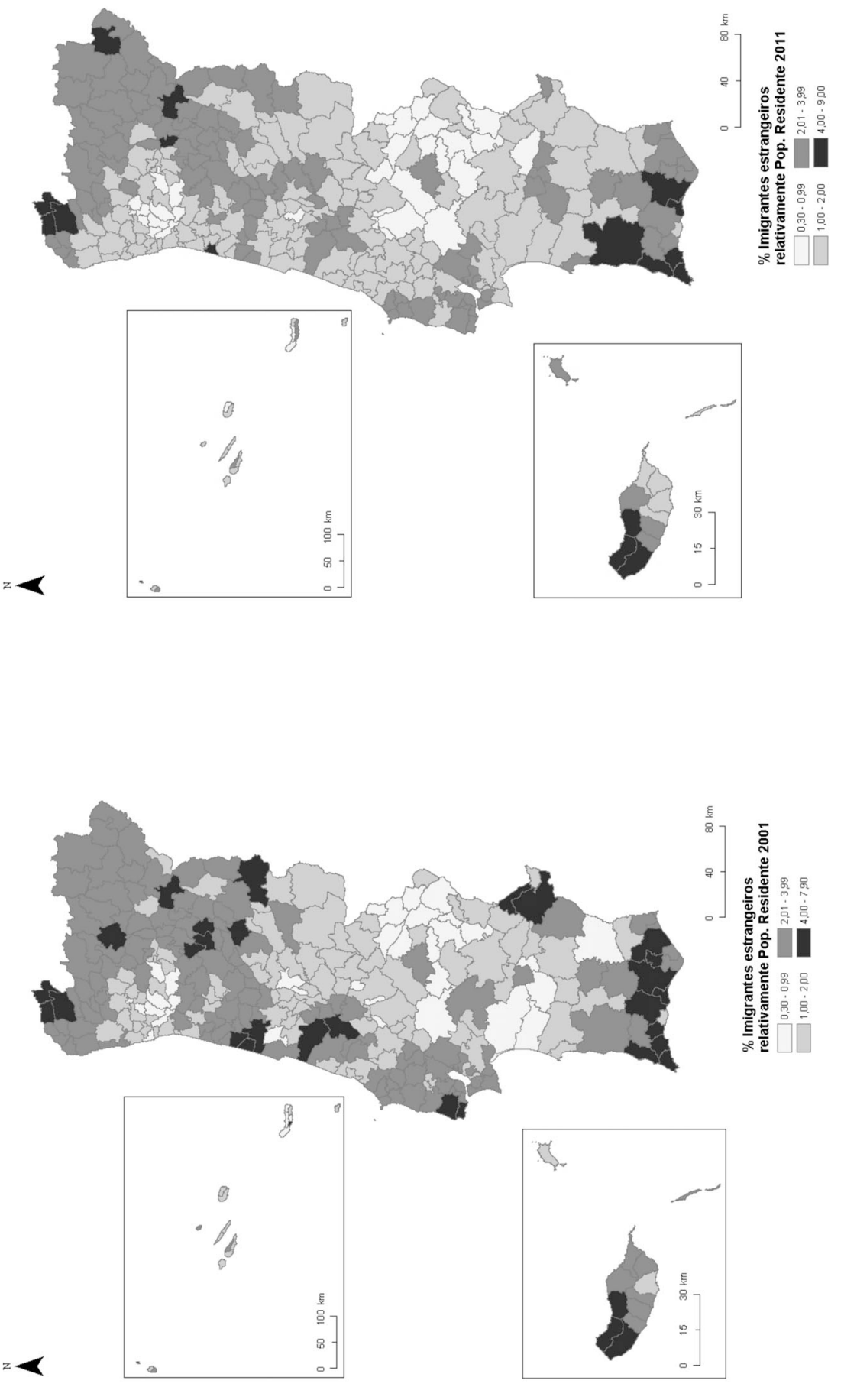

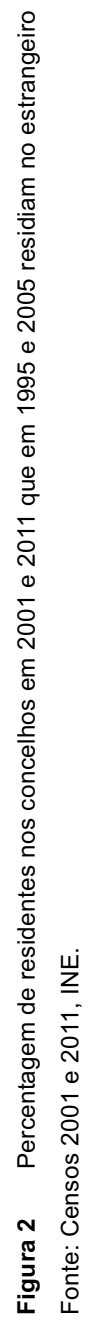




\section{Características dos migrantes em 2001}

Numa análise mais aprofundada vamos agora deter-nos na informação de que dispomos sobre os migrantes internos e, ainda, sobre os imigrantes, olhados através dos residentes por concelho em 2001. A primeira conclusão que podemos tirar do quadro 1 é que $9 \%$ (mais de 900 mil indivíduos) da população residente em Portugal em 2001 vivia, cinco anos antes, em outro concelho, ou no estrangeiro. É um valor significativo e mais significativo se torna quando verificamos que $6,6 \%$ correspondiam a migrantes internos.

Observando agora a estrutura etária dos migrantes internos, e como seria de esperar, é no grupo dos 25-39 anos que estes migrantes se concentram (44,3\%), logo seguido dos migrantes dos grupos de idades dos 40-64 anos e 15-24 anos. Considerando ainda o grupo mais expressivo, podemos constatar que os indivíduos dos 25-39 anos que viviam em outro concelho em 1995, correspondiam a perto de $13 \%$ da população do respetivo grupo etário no Censo 2001. Também a percentagem de migrantes dos 0-14 anos (12,1\%) nos permite deduzir que parte desta mobilidade total poderá corresponder a um efeito de mobilidade familiar.

No que respeita à população residente de 2001 que em 1995 vivia no estrangeiro, e não deixando de relembrar que neste conjunto estão nacionais e estrangeiros, de novo encontramos a maior mobilidade no grupo dos 25-39 anos. Será aqui útil relembrar que em 1995 se está em pleno período de aumento da imigração em Portugal (SEF, 2013) induzida por todo um programa de obras que decorre a partir dos primeiros anos da década de 1990. Mesmo sem distinguir entre regresso de nacionais e fixação de estrangeiros, não é difícil perceber porque é que os dois grupos de idades melhor representados são os dos 25-39 e dos 40-64 anos, isto é, os indivíduos em plena idade ativa. De ressaltar ainda a expressividade dos dois grupos de idades mais jovens (0-14 e 15-24 anos), no contexto do total dos indivíduos que em 1995 viviam fora do país.

Quanto à situação perante a atividade, entre todos os residentes em 2001 que em 1995 residiam em outro concelho, o quadro 2 permite-nos uma primeira leitura, mantendo a análise com os grupos de idades já definidos. Podemos assim constatar que quase $61 \%$ destes migrantes estavam empregados, $4,5 \%$ estavam desempregados e $34,8 \%$ eram inativos.

No grupo etário dos 0-14 anos todos surgem como inativos, como seria de esperar e a legislação implica. Ainda é de ressaltar que em 2001 os migrantes internos do grupo de idades dos 25-39 anos detinha as mais elevadas percentagens quer de migrantes empregados $(38,5 \%)$, quer de migrantes desempregados $(2,3 \%)$, neste último caso correspondendo a 15.442 indivíduos.

Ainda face ao total de indivíduos que no final de 1995 residiam em concelho diferente do de 2001, os mais velhos eram quase exclusivamente inativos.

Numa análise que privilegie a pertença aos grupos de idades trabalhados, podemos ainda deduzir algumas características desta população.

No grupo de idades dos 15-24 anos, cerca de 51\% estavam empregados, 7,4\% desempregados e $41,7 \%$ inativos, o que pode indiciar uma presença significativa de estudantes entre este grupo. 
Quadro 1 População de 2001 que em 31/12/1995 residia em outro concelho ou no estrangeiro, segundo a idade

\begin{tabular}{|c|c|c|c|c|c|c|c|c|}
\hline \multirow{2}{*}{$\begin{array}{l}\text { Grupo } \\
\text { de idades }\end{array}$} & \multicolumn{2}{|c|}{$\begin{array}{l}\text { População } \\
\text { Censo } 2001\end{array}$} & \multicolumn{3}{|c|}{$\begin{array}{l}\text { População que vivia em outro } \\
\text { concelho em 31/12/1995 }\end{array}$} & \multicolumn{3}{|c|}{$\begin{array}{c}\text { População que vivia no estrangeiro } \\
\text { em } 31 / 12 / 1995\end{array}$} \\
\hline & $\mathrm{N}$ & $\%$ & $\mathrm{~N}$ & $\%$ & $\begin{array}{l}\text { \% em relação } \\
\text { ao grupo etário } \\
\text { em } 2001\end{array}$ & $\mathrm{~N}$ & $\%$ & $\begin{array}{l}\text { \% em relação } \\
\text { ao grupo etário } \\
\text { em } 2001\end{array}$ \\
\hline $0-14$ & 1.656 .602 & 16,0 & 82.292 & 12,1 & 5,0 & 32.340 & 13,2 & 2,0 \\
\hline $15-24$ & 1.479 .587 & 14,3 & 112.213 & 16,5 & 7,6 & 43.311 & 17,7 & 2,9 \\
\hline $25-39$ & 2.346 .899 & 22,7 & 301.209 & 44,3 & 12,8 & 83.034 & 33,9 & 3,5 \\
\hline $40-64$ & 3.179 .536 & 30,7 & 133.197 & 19,6 & 4,2 & 71.511 & 29,2 & 2,2 \\
\hline $65 e+$ anos & 1.693 .493 & 16,4 & 50.983 & 7,5 & 3,0 & 14.859 & 6,1 & 0,9 \\
\hline Total & 10.356 .117 & 100,0 & 679.894 & 100,0 & 6,6 & 245.055 & 100,0 & 2,4 \\
\hline
\end{tabular}

Fonte: Censo 2001, INE.

Quadro 2 População de 2001 que em 31/12/1995 residia em outro concelho, segundo a situação na atividade e a idade $(\%)$

\begin{tabular}{|c|c|c|c|c|c|c|}
\hline Situação na atividade económica & $0-14$ anos & $15-24$ anos & 25-39 anos & $40-64$ anos & $\begin{array}{c}65 \mathrm{e} \\
+ \text { anos }\end{array}$ & Total \\
\hline Com atividade - empregados & 0,0 & 8,4 & 38,5 & 13,4 & 0,3 & 60,7 \\
\hline Com atividade - desempregados & 0,0 & 1,2 & 2,3 & 1,0 & 0,0 & 4,5 \\
\hline Inativos & 12,1 & 6,9 & 3,5 & 5,1 & 7,2 & 34,8 \\
\hline Total & 12,1 & 16,5 & 44,3 & 19,6 & 7,5 & 100,0 \\
\hline
\end{tabular}

Fonte: Censo 2001, INE.

No grupo etário seguinte (25-39 anos), quase $87 \%$ estão empregados, o que poderá indiciar que a mobilidade neste grupo etário se deverá fundamentalmente a motivos de emprego. Esta constatação também parece ser verdadeira para o grupo seguinte, dos 40-64 anos, embora de forma um pouco menos evidente. Ainda relativamente ao grupo de idades dos 25-39 anos vale a pena referir que os inativos, que correspondem apenas a $8 \%$ do grupo etário, são maioritariamente indivíduos sem qualificações, ou apenas com o ensino básico. De forma ainda mais expressiva, verificamos que no grupo dos 40-64 anos a percentagem de inativos $(26,1 \%)$ é constituída em grande parte por indivíduos que detêm no máximo o ensino básico $(17,0 \%)$.

O grupo etário dos 40-64 anos exigirá, no prosseguimento desta investigação, uma atenção particular, de forma a perceber as suas características, dado que a percentagem de inativos é muito elevada para indivíduos em mobilidade e, também, porque estes inativos são fundamentalmente detentores apenas do $1 .{ }^{\circ}$ ciclo do ensino básico.

No caso dos indivíduos com 65 e mais anos, e tal como era expectável, a percentagem dos empregados que se movimentaram entre as duas datas em análise é baixa $(4,3 \%)$ e não existem desempregados, incidindo a mobilidade em indivíduos já sem atividade em 2001 (95,7\%). É ainda o grupo de idades, com a exceção dos 
menores de 15 anos, aonde se concentram as mais baixas qualificações. Aliás, observando os indivíduos ainda empregados neste grupo etário, verificamos que o maior contingente pertence aos detentores de apenas o 1. ciclo do ensino básico, $\mathrm{o}$ que corresponde à imagem que temos da necessidade, neste grupo etário, de permanecer a trabalhar, ou seja, são os de qualificações mais baixas que têm necessidade de continuar a trabalhar para além do que seria a idade da reforma. Não esquecer todavia que estes indivíduos (os de 65 e mais anos) representam apenas 7,5\% do total de indivíduos que se movimentaram em 1995 em relação a 2001.

Para analisar as habilitações destes migrantes internos é necessário ter em atenção que algumas das categorias assumem um significado completamente distinto quando cruzadas com os grupos de idades. De facto, não tem o mesmo significado "não saber ler nem escrever", ou "saber ler e escrever sem possuir qualquer grau" no caso do grupo dos 0-14 anos ou no caso de qualquer dos outros grupos etários. No grupo das crianças e jovens, tal significa apenas que, ou ainda nem têm idade para ler e escrever, ou que, "sabendo ler e escrever", se encontram a frequentar o 1. ${ }^{\circ}$ ciclo do ensino básico sem possuírem ainda nenhum grau de ensino. Para os outros graus de ensino, neste grupo de idades, significa apenas que estão no seu percurso escolar. Ou seja, em princípio os indivíduos deste grupo etário acompanharam a família na sua migração interna.

Para os restantes grupos de idades destes migrantes internos faremos a análise das habilitações cruzadas com a situação perante a atividade, por isso tornar mais claro o significado da mobilidade desta população.

O grupo de idades mais difícil de interpretar é o dos migrantes entre os 15 e os 24 anos. Aí se encontrarão quer estudantes de diferentes graus de ensino, quer indivíduos já na vida ativa. Mais de $50 \%$ dos indivíduos deste grupo etário encontravam-se empregados e, quanto às suas qualificações, situavam-se entre os detentores do $2 .{ }^{\circ}$ e do $3 .{ }^{\circ}$ ciclo do ensino básico e do ensino secundário, predominando os detentores do 3. ${ }^{\circ}$ ciclo. Embora os desempregados constituíssem apenas 7,4\% do grupo etário, também as suas qualificações seguiam as mesmas linhas de força. É nos inativos que vamos encontrar $42 \%$ deste grupo etário, com predominância para os detentores do 3. ․ ciclo do ensino básico e secundário. Ou seja, estamos perante um grupo que maioritariamente estaria ainda a prosseguir estudos. No entanto, encontramos ainda neste grupo de inativos dos 15-24 anos um número, que não pode deixar de ser significativo, de indivíduos que detêm apenas o $2 .$. ciclo do ensino básico ou habilitações inferiores (ao todo 10\% do grupo etário), revelando as dificuldades no cumprimento da escolaridade obrigatória em época muito recente. Embora não seja aqui abordada, estes resultados podem também remeter para a problemática dos "nem-nem", isto é, dos jovens que não estudam nem trabalham permanecendo, por isso, numa situação de inatividade. A realidade encontrada para os migrantes internos enquadra-se no contexto nacional, tal como pudemos verificar a partir dos cálculos realizados com os dados do quadro 6.04 do Censo 2001 ("População residente, segundo o grupo etário por nível de instrução e sexo", ver INE, 2002: 110) para o total da população do grupo dos 15-24 anos: 30,4\% deste grupo etário tinha habilitações inferiores à escolaridade obrigatória de 2001 ( $3 .{ }^{\circ}$ ciclo do ensino básico). 
Como seria de esperar é no grupo etário dos 25-39 anos que vamos encontrar os indivíduos com as qualificações mais elevadas. Cerca de $26 \%$ têm habilitações superiores ao ensino secundário e quase $25 \%$ completaram o secundário, ou seja, mais de 50\% destes indivíduos tinham em 2001 habilitações superiores à escolaridade obrigatória. No cruzamento destas características com a situação perante a atividade é também neste grupo de idades que se encontra a maior percentagem de indivíduos empregados. É assim que, na leitura cruzada das habilitações e da situação perante a atividade, se encontram naturalmente na situação de empregados os mais qualificados, constituindo os detentores de qualificações superiores ao ensino secundário $24,6 \%$ do total do grupo etário. Igualmente é de destacar que nos detentores de qualificações superiores ao ensino secundário apenas 1,25\% do grupo etário estão desempregados ou inativos. No caso deste grupo de idades, a inatividade concentra-se nos detentores de qualificações mais baixas $\left(4,1 \%\right.$ com menos do que o $3 .{ }^{\circ}$ ciclo).

Os indivíduos dos 40-64 anos manifestam uma estrutura global de qualificações que se revela inferior à do grupo de idades dos 25-39 anos, apesar de estarmos aqui perante um grupo com uma muito maior extensão do leque de idades (leque de 25 anos contra 15 do grupo etário anterior). Apesar disso, o grupo de idades dos 40-64 anos surge ao nível do total de indivíduos em análise no segundo lugar em volume, o mesmo valendo para o total de empregados. Neste caso apenas $18 \%$ têm qualificações superiores ao ensino secundário e 15,3\% têm apenas o secundário. No entanto, é neste grupo de idades que, face à população em análise, se encontra o maior número e a percentagem mais elevada de doutorados em mobilidade, apesar do seu quantitativo ser diminuto. É nos detentores de apenas o $1 .{ }^{\circ}$ ciclo do ensino básico que se observa a maior percentagem de desempregados ( $2,0 \%$ do grupo). É também de salientar a percentagem de inativos que, percorrendo todos os níveis de qualificações, encontram a sua máxima expressão nos detentores do ensino básico (1.. , 2.ำ e 3.ำ ciclos) e secundário (19,6\% do grupo etário), bem como daqueles que não detêm qualquer grau de ensino (4,3\%). Esta situação de inatividade dos indivíduos que tiveram um processo de mobilidade recente deve merecer uma análise que permita uma melhor compreensão.

No último grupo de idades (65 e mais anos) existe a estrutura de qualificações mais baixa dos indivíduos em mobilidade interna, com $78 \%$ deste grupo etário apenas com o 1. ${ }^{\circ}$ ciclo ou sem quaisquer habilitações. Apesar da dimensão deste valor constata-se que este é menos gravoso do que o da população em geral deste grupo etário, dado que em 2001 os indivíduos sem quaisquer qualificações ou apenas com o 1. ${ }^{\circ}$ ciclo do ensino básico representavam $84,7 \%$ da população deste grupo etário, segundo o cálculo feito a partir do quadro 6.04 do Censo 2001 (INE, 2002: 110). Como seria de esperar a maioria dos indivíduos com 65 e mais anos em 2001, e que em 1995 viviam em outro concelho, encontram-se em situação de inatividade (quase $96 \%$ ). Embora a análise da população residente em 2001 num qualquer concelho e que em 1995 residisse no estrangeiro assuma um significado muito diferente relativamente à mobilidade interna, foi trabalhada exatamente da mesma forma. Esta opção prende-se com o facto de as características comparativas serem elucidativas relativamente à tipologia destes migrantes e à atração que os concelhos poderão induzir. Já vimos atrás, através da figura 2, que a sua distribuição no território difere 
Quadro 3 População de 2001 que em 31/12/1995 residia no estrangeiro, segundo a idade e a situação na atividade $(\%)$

\begin{tabular}{lrrrrrr}
\hline Situação na atividade económica & $0-14$ anos & $15-24$ anos & $25-39$ anos & $40-64$ anos $\begin{array}{c}65 \text { e } \\
+ \text { anos }\end{array}$ & Total \\
\hline Com atividade - empregados & 0,0 & 8,5 & 26,0 & 14,4 & 0,3 & 49,1 \\
Com atividade - desempregados & 0,0 & 1,5 & 2,6 & 1,5 & 0,0 & 5,5 \\
Inativos & 13,2 & 7,7 & 5,4 & 13,3 & 5,8 & 45,4 \\
Total & 13,2 & 17,7 & 33,9 & 29,2 & 6,1 & 100,0 \\
\hline
\end{tabular}

Fonte: Censo 2001, INE

substancialmente da distribuição dos migrantes internos, quer em 2001 relativamente a 1995, quer em 2011 relativamente a 2005.

Tal como para os migrantes internos só possuímos dados de caracterização para o Censo 2001. Convém ainda relembrar que enquanto os migrantes internos correspondiam a $6,6 \%$ da população recenseada (679.894 indivíduos), os residentes de 2001 que viviam no estrangeiro em 31/12/1995 correspondiam apenas a 2,4\% dos recenseados (245.055 indivíduos). Ou seja, estamos a analisar uma população muito mais reduzida.

Quando analisamos a situação face à atividade do total destes indivíduos, encontramos uma realidade que se aproxima da situação dos migrantes internos (quadro 3). A maioria está empregada, seguida de perto pelos inativos e, com um valor remanescente, pelos desempregados. De qualquer forma, refira-se que a percentagem de empregados é menor e a de inativos é superior, quando comparadas com as dos migrantes internos (ver quadro 2).

A comparação do quadro 3 com o quadro 2 permite ainda perceber que, proporcionalmente, os grupos jovens, quer dos 0-14 anos quer dos 15-24 anos, são ligeiramente superiores aos migrantes internos, a indiciar uma imigração familiar. No caso deste último grupo de idades (15-24 anos), a percentagem de inativos é também superior à dos migrantes internos, indiciando neste caso uma permanência no sistema de ensino.

Os valores do quadro 3 permitem ainda verificar que, do total de empregados, a maior fatia se situa no grupo de idades dos 25-39 anos, a corresponder a $26 \%$ relativamente ao total desta população. Quanto aos migrantes internos, a maior diferença pode ser encontrada na percentagem total de inativos $(45,4 \%$ contra $34,8 \%$ nos migrantes internos), com o valor mais significativo (se excetuarmos o grupo dos jovens ainda sem idade escolar ou em idade escolar) a situar-se no grupo de idades dos 40-64 anos e não, como nos migrantes internos, no grupo dos de 65 e mais anos. Percentualmente é no grupo de idades dos 40-64 anos que verificamos que, relativamente aos empregados e aos desempregados, as percentagens são idênticas às dos migrantes internos. No caso dos inativos os valores são proporcionalmente inferiores $(13,3 \%$ de migrantes do estrangeiro inativos, contra $5,1 \%$ para o caso dos migrantes internos inativos).

Também a carecer de um estudo mais aprofundado estará a percentagem total de desempregados entre os imigrantes $(5,5 \%)$ contra a dos migrantes internos $(4,5 \%)$, verificando-se o mesmo qualquer que seja o grupo etário. 
Assim, o que se revela mais interessante nesta análise global é o facto de os residentes vindos do estrangeiro, entre o início de 1996 e 2001, integrarem percentagens significativas de jovens e de inativos no grupo dos 40-64 anos, a apontar para a necessidade de estudos mais aprofundados que tenham em consideração os concelhos de fixação destes imigrantes, em conjugação com a sua situação perante a atividade.

Relativamente à situação perante a atividade, em que a análise se centra agora nos totais para os diferentes grupos de idades, a primeira observação diz respeito à sua comparação com os correspondentes dos migrantes internos, ao verificar que, embora com valores diferentes, as linhas de força em cada grupo etário relativamente à sua situação na atividade são idênticas.

São também de realçar os valores dos inativos, considerando as percentagens nos grupos dos 25-39 anos e dos 40-64 anos (15,8 e 45,7\%), dado que em termos proporcionais representam quase o dobro das encontradas para os migrantes internos, em cada um dos grupos etários.

De igual modo, e alertando para a investigação futura, as percentagens de desempregados nos grupos dos 15 aos 64 anos, para quem imigrou ou regressou ao país entre 1996 e 2001, parecem particularmente elevadas. Uma análise segundo o sexo, que não elaborámos nesta primeira aproximação às características destes migrantes, talvez ajudasse a interpretá-las. No entanto, globalmente, qualquer que seja o grupo etário de pertença, os migrantes que nos chegaram nesta época vieram para trabalhar e estudar ou eventualmente para gozar a reforma. A leitura conjunta com as habilitações, que faremos de seguida, poderá elucidar-nos um pouco mais, não só sobre estes aspetos, mas também no seu cruzamento com a situação perante a atividade que acabámos de ver.

Quando analisamos as habilitações dos residentes de 2001 que em 1995 se encontravam a residir no estrangeiro, vamos globalmente encontrar similitudes com as habilitações dos migrantes internos. No entanto, uma leitura mais atenta faz ressaltar algumas diferenças dignas de assinalar.

Saliente-se, pela sua especificidade, o facto de percentualmente, dos 25 anos em diante, o peso dos doutorados ser superior em qualquer dos grupos etários considerados. Para além disso, quando esta variável é cruzada com a situação na atividade, essa diferença torna-se ainda mais expressiva, embora se esteja a lidar com números absolutos relativamente baixos face ao total de indivíduos em cada um desses grupos etários. De facto, no grupo dos 25-39 anos encontram-se 0,82\% de doutorados empregados, contra $0,20 \%$ para o caso dos migrantes internos. Do mesmo modo, no grupo dos $40-64$ anos eles são $0,63 \%$ para os que vieram do estrangeiro, contra $0,54 \%$ para os migrantes internos. Observando os números absolutos este fenómeno é ainda mais interessante. O total de migrantes do estrangeiro é cerca de três vezes menor do que o total de migrantes internos e, no entanto, o total de doutorados empregados vindos do exterior é superior (678) ao dos doutorados empregados que migraram internamente (588) no grupo de idades dos 25-39 anos. Este facto revela a captação de doutorados nacionais e de outras nacionalidades que vieram do estrangeiro e estavam a trabalhar no nosso país. Em 2001 os valores dos doutorados empregados vindos do estrangeiro (1144) tornam-se ainda mais 
expressivos quando sabemos que o Censo 2001 recenseou 13.262 doutorados no país, independentemente da sua situação perante a atividade. Já deduzimos relativamente à mobilidade interna que existem doutorados inativos, o que significará que entre aqueles 13.262 existirão indivíduos que provavelmente se encontravam em processo de pós-doutoramento, logo considerados aqui como inativos. Ou seja, os 1144 doutorados empregados residentes em Portugal e que em 31/12/1995 ainda residiam no estrangeiro representavam $8,6 \%$ do total de doutorados residentes no país. Se considerarmos todos os doutorados que entraram no país e que naquela data ainda residiam no estrangeiro (1423), e em que se incluem os empregados, os desempregados e os inativos, a respetiva percentagem no total de doutorados no país em 2001 atinge os 10,7\%.

Do total da população em estudo os detentores do 1.ำ ciclo do ensino básico constituem o maior grupo, sendo a sua concentração muito elevada nos grupos de idades dos 40-64 e 65 e mais anos. No grupo dos 40-64 anos estes indivíduos encontram-se quase igualmente distribuídos entre empregados e inativos. Ou seja, parecem existir aqui duas categorias de pessoas: provavelmente os mais jovens do grupo etário ainda se encontram a trabalhar, enquanto que os mais velhos já estarão reformados. A percentagem de desempregados neste grupo etário é diminuta.

Ainda entre os detentores do $1 .^{\circ}$ ciclo do ensino básico, os indivíduos de $65 \mathrm{e}$ mais anos encontram-se maioritariamente $(32,2 \%)$ já inativos. É também neste grupo etário e na situação perante a atividade que surgem as percentagens mais significativas de indivíduos que "sabem ler e escrever sem possuir qualquer grau de ensino" e que "não sabem ler nem escrever" $(45,5 \%)$, se não considerarmos o grupo de idades dos 0-14 anos.

Mantendo-nos ainda nos inativos e nos dois grupos de idades mais velhos, podemos verificar que percentualmente as suas habilitações são superiores às dos indivíduos da mobilidade interna. Este facto parece apontar para um contigente relativamente significativo de indivíduos estrangeiros que se instalam em Portugal já reformados e que possuem níveis de ensino um pouco superiores aos nacionais e, provavelmente, também a reformados de nacionalidade portuguesa que regressam ao país melhor habilitados do que partiram, a par daqueles que regressam com as mesmas qualificações com que saíram.

No grupo de idades dos 15-24 anos, entre os empregados encontram-se apenas $4,2 \%$ detentores de habilitações superiores ao secundário e, de forma mais expressiva, os detentores do secundário e do 3. ${ }^{\circ}$ ciclo do ensino básico (30,0\%). Com uma expressão um pouco maior, no grupo de idades dos 25-39 anos os empregados com habilitações superiores ao ensino secundário são 13,9\%, surgindo os detentores do secundário com $17,1 \%$ e depois, com percentagens muito similares, cerca de $14 \%$, os detentores de cada um dos três ciclos do ensino básico. Este valores, para estes grupos de idades, parecem apontar para dois grupos diferenciados de migrantes do exterior que se encontravam empregados em 2001, com percentagens pouco significativas de indivíduos sem nenhum grau de ensino, mas também com percentagens pouco significativas de indivíduos com habilitações mais elevadas. A exceção face aos valores nacionais já foi referida e corresponde aos doutorados. 
Complementarmente pode ainda referir-se que se considerarmos os níveis de habilitações, em 2001, do total da população residente e da população que em 1995 residia em outro concelho ou no estrangeiro, é particularmente interessante o facto de, globalmente, ser mais elevado o nível de habilitações entre os que mudaram de concelho de residência no país. No entanto, quando se atenta nos indivíduos com residência no estrangeiro em 1995, embora sejam mais expressivos os níveis mais elevados, doutoramento e mestrado, os restantes níveis são inferiores aos que se encontram entre os indivíduos envolvidos nos fluxos internos e mesmo entre o total da população recenseada (segundo o quadro 6.04 do Censo 2001 - INE 2002: 110). Ou seja, os migrantes internos têm níveis de habilitações mais elevados, comparativamente com o que se encontra na população portuguesa, que, por sua vez, apresenta níveis superiores aos daqueles que tiveram residência no estrangeiro, excetuando, como aliás se salientou, o que acontece entre os detentores de doutoramento e mestrado que vieram do estrangeiro.

Atendendo à distribuição das habilitações por grupos de idades pode mencionar-se um efeito geracional, uma vez que se verifica que, progressivamente, os níveis de habilitações vão crescendo entre os mais jovens.

Considerando a situação na profissão, é entre os que mudaram de residência em Portugal que se encontram proporções mais significativas de pessoas com atividade e empregadas, por grupo de idades, com exceção no grupo de idades de 65 e mais anos. Já os desempregados são mais expressivos entre os que tiveram residência no estrangeiro, sendo de notar, ainda, a presença de desempregados no grupo dos maiores de 65 anos.

De ressaltar que no grupo dos de 65 e mais anos a percentagem de ativos no país é superior à que se encontra entre os que mudaram de residência no país ou que vieram do estrangeiro, a poder indiciar uma mobilidade relacionada com a reforma.

Ou seja, entre os que mudaram a residência no país movimentaram-se mais os que tinham maiores habilitações e demonstraram uma maior capacidade, ou possibilidade, de exercício de atividade económica. Complementarmente, os inativos são mais expressivos entre os que vieram do estrangeiro, com exeção do grupo etário dos 15-24 anos, o que pode advir do facto se tratar de um grupo de idades em que muitos indivíduos ainda estão em formação académica.

\section{Conclusão}

Esta análise preliminar fez-nos perceber a importância da investigação sobre a mobilidade interna, registada através dos censos, e a necessidade do seu aprofundamento, principalmente no que aqui não foi sequer aflorado, ou seja, no que respeita aos movimentos internos interessa perceber as linhas fundamentais de atração e repulsão, pois os movimentos a nível concelhio assumem, na nossa perspetiva, uma enorme importância. Acresce a necessidade de atender às diferenças entre os sexos que aqui não foram abordadas. Seguramente que perceber quem se move ajuda a compreender porque se move e permite ir mais longe na caracterização de 
uma realidade fluida e sobre a qual os trabalhos que têm sido produzidos apenas analisam aspetos parcelares, seja a nível da temática, seja a nível regional.

No entanto, embora tenham sido destacadas importantes dimensões inerentes às migrações internas, considerando os efeitos na dinâmica populacional com impactos diversificados a nível demográfico, socioeconómico e regional, falta uma continuidade na análise, quer para o todo nacional, quer em termos temporais, de forma a apreender a evolução e o sentido dos fluxos migratórios internos, assim como as caraterísticas dos migrantes e os fatores de atração e/ou repulsão e sua permanência ou transformação. Importa, também, não descurar os contornos em que estes movimentos ocorrem, tal como Maria Roca e Dulce Pimentel salientam: "a diversificação das dinâmicas territoriais relacionadas com as migrações internas são um reflexo da ação, raramente isolada, de fatores complexos e multidimensionais" (2003: 94).

Assim, num país profundamente marcado pelos fenómenos migratórios, com grandes repercussões ao nível da dinâmica da população, é importante não perder de vista, pelo que representa do ponto de vista dos comportamentos, a mobilidade e os fluxos internos, bem como os fluxos que envolvem residentes vindos do estrangeiro que começámos a debater.

É, por isso, necessário destacar, pela sua dimensão, a movimentação que se processa no interior do país, visível a partir dos dados de 2001 e 2011. Em qualquer destes recenseamentos, mais de $6 \%$, do total dos residentes num determinado concelho, migraram em data anterior pelo menos uma vez, e mais de $2 \%$ dos que o fizeram, tinham residência no estrangeiro. Estes números são, para a nossa dimensão, particularmente significativos, pela expressão e impacto que regionalmente pressupõem. A uma escala local esta variação é muito significativa, como aliás é percetível nos cartogramas, e traduz dinâmicas muito diferenciadas que estão subjacentes às mudanças no tecido socioeconómico, ou que acabam por impulsionar as alterações neste tecido.

Sumariando, podemos referir que, em 2001, relativamente à residência em 1995, os que se moveram, no território nacional, dispunham de mais habilitações do que a média da população portuguesa nos mesmos grupos etários, mostrando-se, assim, mais ativos. Estes resultados vão ao encontro dos apresentados por João Peixoto, que destacou: "que o conjunto dos migrantes é significativamente mais qualificado que a média da população portuguesa" (1998: 80). O mesmo autor verificava, ainda, "um claro aumento da mobilidade com o aumento da educação" (1988: 80 e 81). Mesmo não sendo diretamente relacionados, até porque os contextos dos períodos em análise são diferentes, importa também atender aos residentes que chegaram do estrangeiro. Entre estes podem distinguir-se dois grupos: um constituído por indivíduos com níveis mais elevados de habilitações, mesmo comparativamente à média nacional, e outro, mais expressivo, constituído por indivíduos com níveis de habilitação inferiores à média nacional. É também entre os que mudaram de residência no país que se encontram percentagens mais elevadas de indivíduos a exercer atividade económica. Quer nos migrantes internos, quer nos que vieram do estrangeiro, os desempregados constituem uma categoria com muito menos significado, embora a merecer uma análise mais exigente. Já os 
inativos são mais expressivos entre os que vieram do estrangeiro, sobretudo nos grupos de idades entre os 25-39 anos e os 40-64 anos.

João Peixoto na sua investigação encontrou a maior incidência da mobilidade entre os 25 e os 34 anos, tendo ressaltado uma seletividade migratória que envolveria não só os mais jovens, como também as "profissões intelecutais e científicas" (1998: 82) ou, como designa, as profissões de "topo" e quadros intermédios e atividades ligadas aos serviços (1998: 83). Realçou, todavia, o perigo das generalizações com base nos dados encontrados, devido às condicionantes e conjunturas temporais e espaciais (1998: 83).

Encontra-se também maior mobilidade entre os detentores de níveis mais elevados de habilitações, que simultaneamente demonstraram uma maior capacidade, ou possibilidade, de exercício de atividade. Consideramos que esta mobilidade supõe uma reação aos contextos socioeconómicos, pressupõe e acarreta diferentes dinâmicas territoriais e populacionais, com impactos que se farão sentir ao longo do tempo. Daí esta análise assumir um interesse acrescido, por um lado pela caracterização da população envolvida nos fluxos migratórios, por outro, pela proposta de uma perspetiva alargada ao país e à diferenciação das suas diferentes regiões.

\section{Referências bibliográficas}

Alarcão, A. de (1964), “Êxodo rural e atracção urbana no Continente", Análise Social, II (7-8), pp. 511-573.

Baccaini, B. (1999), "Analyse des migrations internes et estimation du solde migratoire externe au niveau local à l'aide des données censitaries", Population, 54 (4-5), pp. 801-815.

Baccaini, B. (2007), “Les flux migratoires interrégionaux en France depuis cinquante ans", Population, 62 (1), pp. 143-160.

Bell, M., et al. (2002), "Cross-national comparison of internal migration: issues and measures", Journal of the Royal Statistical Society, série A, "Statistics in Society", 165 (3), pp. 435-464.

Bendito, T. V. (1999), “Las migraciones interiores españolas en la segunda mitad del siglo XX", em K. Z. Sangroniz e M. G. Portilla (orgs.), Historia de la Población. IV Congreso de la Asociación de Demografía Histórica, Bilbau, Universidad del País Vasco, Servicio Editorial, pp. 339-370.

Borjas, G. J. (2006), “Native internal migration and the labor market impact of immigration", Journal of Human Resources, 41 (2), pp. 221-258.

Cabré, A., I. Pujadas, e J. Moreno (1985), “Cambio migratorio y reconversión territorial en España", Revista Española de Investigaciones Sociológicas, 32, pp. 43-65.

Cabré, A., e J. Recaño (1997), “Migraciones y coyuntura económica en las regiones españolas: períodos 1988-90 y 1992-94", Papers de Demografía, 121.

Cauchi-Duval, N., V. Jourdan, e C. N’Diaye (2006), “L'impact des migrations des personnes âgées sur les populations des régions françaises", em G.-F. Dumont (org.), Les Territoires Face au Vieillissement en Europe. Géographie-Politique-Prospective, Paris, Ellipses, pp. 138-149. 
Coll, A. G., e R., Puyol (1997), “Las migraciones interiores en España”, em R. Puyol (org.), Dinámica de la Población en España. Cambios Demográficos en el Último Cuarto del Siglo XX, Madrid, E. Sintesis, pp. 167-216.

Cónim, C. N. P. S. (1985), “Migrações internas em Portugal - 1981”, Revista do Centro de Estudos Demográficos, 27, pp. 7-42.

Courgeau, D. (1973), “Migrants et migrations", Population, 28 (1), pp. 95-129.

Courgeau, D., e E. Lelièvre (2003), "Les motifs individuels et sociaux des migrations", em G. Caselli, J. Vallin e G. Wunsch (orgs.), Les Déterminants de la Migration, Paris, INED, pp. 147-169.

Courgeau, D., E. Lelièvre, e G. I. Rogers (2002), “Estimation of French internal migration in the period 1990-1999 and comparison with earlier periods", Population, 59 (5), pp. 703-709.

Dasre, A., et al. (2009), "Sélectivité migratoire des populations selon leur âge et concentrations socio-spatiales", Espace, Populations, Sociétés, 1, pp. 67-84.

Evangelista, J. (1971), Um Século de População Portuguesa (1864-1960), Lisboa, Instituto Nacional de Estatística.

Ferrão, J., (1996), “Três décadas de consolidação do Portugal demográfico 'moderno' ", em A. Barreto (org.), A Situação Social em Portugal, 1960-1995, Lisboa, Instituto de Ciências Sociais, pp. 165-190.

INE (2002), Censos 2001. Resultados Definitivos, Lisboa, INE, disponível em: https://www.ine.pt/ngt_server/attachfileu.jsp?look_parentBoui=58528560\&att_disp lay=n\&att_download=y (última consulta em agosto de 2016).

Lucas, V. (1997), “O retorno de emigrantes: a sua relevância na região Centro”, Cadernos Regionais - Região Centro, 7, pp. 21-47.

Magalhães, M. da G. (2003), “Migrações inter NUTS II e projecções regionais de população", Revista de Estudos Demográficos, 34, pp. 61-71.

Mendes, M. F., A. Caleiro, S. Lagarto, e F. Ribeiro (2009), “O futuro demográfico das regiões: a importância da identificação de padrões em termos de fluxos migratórios internos no espaço continental português", em Cabo Verde - Redes e Desenvolvimento Regional, Cidade da Praia, I Congresso de Desenvolvimento Regional de Cabo Verde, pp. 930-954, disponível em: http://www.apdr.pt/congresso/2009/pdf/Sessão 10/152A.pdf (última consulta em agosto de 2016).

Nicholson, B. (1990), “The hidden component in census-derived migration data: assessing its size and distribution", Demography, 27 (1), pp. 111-119.

Oliveira, C., e J. Peixoto (2001), “Migrações inter-regionais em Portugal Continental, 1992-1999", Revista de Estudos Regionais - Região de Lisboa e Vale do Tejo, 2 (1. ${ }^{\circ}$ semestre), pp. 37-49.

Peixoto, J. (1998), “Selectividade migratória e dinâmicas regionais: as migrações inter-regionais em Portugal nos anos 80", Revista de Estatística (INE), 9, pp. 73-112.

Pinto, M. L. R., e T. Rodrigues (1996), “Migrações internas e emigração no Portugal do século XX", Ler História, 19, pp. 39-49.

Pujadas, I., e A. García Coll (1995), “Migraciones interiores en España: tendências recientes y perspectivas de futuro", Revista de Geografía, XXIX (3), pp. 1-150.

Recaño, J. (2004a), “Las migraciones internas de retorno en España durante la primera mitad de la década de los noventa: implicaciones demográficas y territoriales", Scripta Nova, 
Revista electrónica de geografía y ciencias sociales, VIII (157), disponível em: http://www.ub.edu/geocrit/sn/sn-157.htm\#recaño (última consulta em agosto de 2016).

Recaño, J. (2004b), “Migraciones internas y distribución espacial de la población española", em J. L. Maldonado (org.), Informe sobre la Situación Demográfica en España, Madrid, Fundación Fernando Abril Martorell, pp. 187-230.

Recaño, J. (2006), “Los intercambios poblacionales entre las regiones españolas”, em J. A. F. Cordón e J. L. Maldonado (orgs.), Análisis Territorial de la Demografía Española, Madrid, Fundación Fernando Abril Martorell, pp. 273-318.

Recaño, J., e A. Cabré (2003), “Migraciones interregionales y ciclos económicos en España (1988-2001)", disponível em: http://digitum.um.es/jspui/bitstream/10201/2842/3/12 Cabre 179-197.pdf.txt (última consulta em agosto de 2016).

Roca, M., e D. Pimentel (2003), “Causas prováveis das migrações internas em Portugal na década de noventa”, GeoINova, 8, pp. 91-116, disponível em: http://fcsh.unl.pt/geoinova/revistas/numero8.htm (última consulta em agosto de 2016).

Royer, J. F. (2009), “Estimations des migrations répétées et des migrations de retour dans des sous-populations en France", Population, 64 (4), pp. 797-820.

Saleiro, E., e P. Campos (1994), “As migrações internas na região Norte”, Estatísticas e Estudos Regionais - Região Norte, 6 (setembro-dezembro), pp. 12-32.

Sampaio, D. (2010), “Migrações pós-reforma em áreas rurais de baixa densidade do Algarve: novas teias de mobilidade da população em idade de reforma", em Actas do XII Colóquio Ibérico de Geografia, Porto, Universidade do Porto, disponível em: http://web.letras.up.pt/xiicig/comunicacoes/193.pdf (última consulta em agosto de 2016).

SEF (2013), “Evolução global da população estrangeira, 1980-2013”, disponível em: http://sefstat.sef.pt/evolucao.aspx (última consulta em agosto de 2016).

Maria Cristina Sousa Gomes. Professora auxiliar, Departamento de Ciências Sociais, Políticas e do Território, Unidade de Investigação GOVCOPP, Universidade de Aveiro, Campus de Santiago 3810-193, Aveiro, Portugal. E-mail: mcgomes@ua.pt

Maria João Guardado Moreira. Professora coordenadora, Escola Superior de Educação do Instituto Politécnico de Castelo Branco, Centro de Estudos da População, Economia e Sociedade - CEPESE (Porto), Rua Prof. Dr. Faria de Vasconcelos, 6000-266, Castelo Branco, Portugal. E-mail: mjgmoreira@ipcb.pt

Maria Luís Rocha Pinto. Professora associada, Departamento de Ciências Sociais, Políticas e do Território, Unidade de Investigação GOVCOPP, Universidade de Aveiro, Campus de Santiago 3810-193 Aveiro, Portugal. E-mail: mluispinto@ua.pt

Receção: 24 de fevereiro de 2014 Aprovação: 2 de fevereiro de 2016

SOCIOLOGIA, PROBLEMAS E PRÁTICAS, n. ํㅛ 83, 2017, pp. 55-74. DOI:10.7458/SPP2017833546 